\title{
Praxishygiene
}

\section{Sauberkeit allein genügt nicht}

\author{
Auch wenn das Einhalten von Hygienevorschriften in der Arztpraxis eine \\ Selbstverständlichkeit ist, sollten Sie Ihre Praxis auf mögliche Schwachstellen \\ hin überprüfen. Zieht z. B. ein Patient wegen einer Infektion nach einer \\ Injektion vor Gericht, und die Praxis verfügt über keinen nachweisbaren \\ Hygieneplan, kann dies erhebliche haftungsrechtliche Konsequenzen nach \\ sich ziehen.
}

Z war verfügen die meisten Arztpraxen über einen Desinfektionsplan, der den rechtlichen Anforderungen aber oft nicht genügt, meint René Kinstle, u. a. Hygienebeauftragter für Arztpraxen. Zudem, so Kinstle beim Workshop „Hygiene in der Arztpraxis“im Rahmen der practica in Bad Orb, sollten Praxisteams überprüfen: Ist der Desinfektionsplan, der meist vom Desinfektionsmittelhersteller zur Verfügung gestellt wurde, überhaupt noch passend? Das gilt vor allem, wenn die Praxis inzwischen den Lieferanten gewechselt hat.

\section{Desinfektionsmittelhersteller übertreiben gern}

Außerdem weiß Kinstle aus Praxisbegehungen: Bei der Notwendigkeit des Desinfizierens übertreiben die Hersteller gern ein bisschen. Kein Wunder, dass mitunter etwa empfohlen wird, die Flächen des Eingangsbereichs der Praxis regelmäßig zu desinfizieren, wird doch so ordentlich Mittel verbraucht. Da kann man ja gleich auf den Marktplatz spazieren und dort weitermachen, kritisiert Kinstle.

Im Vergleich zum Desinfektionsplan verfügen nur wenige Praxen über einen Hygieneplan, wie die Teilnehmer des practica-Workshops per Handzeichen bestätigen (ca. 10\%).

\section{Ein Hygieneplan ist mehr als ein Desinfektionsplan}

Die Anforderungen an einen Hygieneplan sind recht umfassend. Ärzte können einen solchen Plan durch einen Dienstleister erstellen lassen (die Kosten dafür liegen laut Kinstle bei ca. 350 bis 400
Euro) oder sich mit Entwürfen auseinandersetzen, die beispielsweise unter www.bgw-online.de oder beim Gesundheitsamt der Stadt Frankfurt/Main zu finden sind.

Der Hygieneplan enthält die Verantwortlichen für die Hygiene (plus Stellvertreter!), die Rechtsgrundlagen sowie Informationen zu den Arbeitsabläufen und den benötigten Materialien. Zudem werden im Hygieneplan auch Maßnahmen zur Personalhygiene (Arbeits- und Schutzkleidung, Händehygiene, Handschuhe - wann zu tragen?) sowie zur Flächendesinfektion und Reinigung dargestellt. Wichtig ist zudem eine jährliche Mitarbeiterschulung in Hygienefragen.

Entscheidend, so Kinstle, sei die richtige Händedesinfektion. Würde diese korrekt und regelmäßig durchgeführt, könnten schon viele Probleme im Gesundheitswesen vermieden werden. Schließlich sind die Hände das „wichtigste Arbeitsmittel“ und gleichzeitig aber auch der größte Keimträger. Wie man eine hygienisch korrekte Händedesinfektion durchführt, wird zum Beispiel auf einem Video der www.mrsa-net.de (Deutsch-Niederländisches Präventionsprojekt zur Bekämpfung von methicillinresistentem Staphylococcus aureus) unter der Rubrik „FAQ“ gezeigt. Interessierte finden dort die Antworten zu rund 150 praxisnahen Fragen zu den Themen Hygiene und Desinfektion.

\section{Sind Sie ein „Håndeschüttler"?}

Gerade in Zeiten von Influenza und grippalen Infekten sollte Händeschütteln grundsätzlich vermieden werden. Verfügt eine Praxis über zwei Warteräume, können „Kranke“ und „Gesunde“ voneinander getrennt werden. Oft lässt sich auch die Terminvergabe so regeln, dass etwa die an Erkältung oder Grippe Erkrankten für die Abendstunden einbestellt werden.

Die Hygieneanforderungen einer Arztpraxis müssen wirklich allen Beteiligten verdeutlicht werden, rät Kinstle. So zeigte sich im Rahmen einer Praxisbegehung, dass viele Flächen in der Praxis kontaminiert waren. Und das, obwohl die Ärzte und das Praxisteam auch im Rahmen von QM - vorbildlich die Hygienemaßnahmen einhielten. Wie sich herausstellte, hatte die Putzfrau dieselben Wischlappen für alle möglichen Flächen benutzt und abends einfach feucht in den Putzeimer gelegt. Die Lappen wurden erst nach mehreren Tagen ausgetauscht. So konnten sich die Keime munter vermehren und wurden bei der abendlichen Reinigung der Praxis überall verteilt.

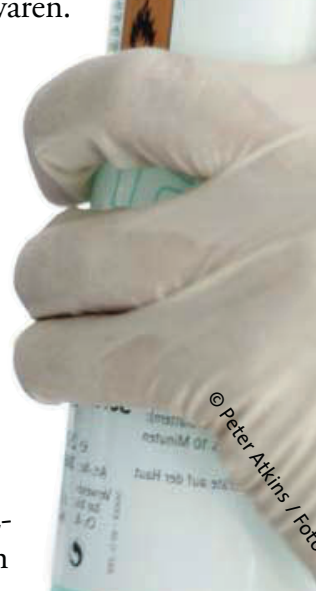

